\title{
Edible mushrooms of Mizoram
}

\author{
Hmar Lalrinawmi ${ }^{1}$, Josiah M.C. Vabeikhokhei ${ }^{1}$, John Zothanzama ${ }^{1 *}$, Zohmangaiha $^{1}$ \\ IDepartment of Environmental Sciences, Mizoram University, Tanhril 796004, Mizoram, India
}

\begin{abstract}
Twenty-seven (27) species of edible mushrooms growing in both soil and wood have been described here from Mizoram, India. All the species were identified based on their morphological, both macro- and microscopic characteristics. The study was carried out during July 2013 to October 2016. Wood inhabiting fungi viz. Schizophyllum commune (pasi), Lentinula lateritia (pa pal), Auricularia auricular-judae (Pu Vana beng), Lentinus tigrinus (pa hnahkhar), L. polychrous (pa chang/pa puanveng) and soil growing fungi viz., Lactifluus corrugis (pa uithin), Lactarius piperatus (pa lengvar), Macrolepiota dolichaula (pa se-ek), Russula subfragiliformis (pa lengsen), Termotomyces heimii (pa sawntlung), Volvariella taylorii (changel pa) are the edible species known to the local community. Other edible species yet unknown to the local community in Mizoram are also recorded viz., Cantharellus cibarius, Craterellus cornucopioides, Lycoperdon perlatum, Macrolepiota procera, Ramariopsis kunzei, Russula aurora, $R$. compacta, $R$. cyanoxantha, Lentinula edodes, Lentinus sajor-caju, Pleurotus ostreatus, $P$. djamor, Tremella fuciformis, T. mesenterica, Laetiporus suphureus and Fistulina hepatica.
\end{abstract}

Key words: Microscopy; morphology; mushrooms; spore; sporocarp.

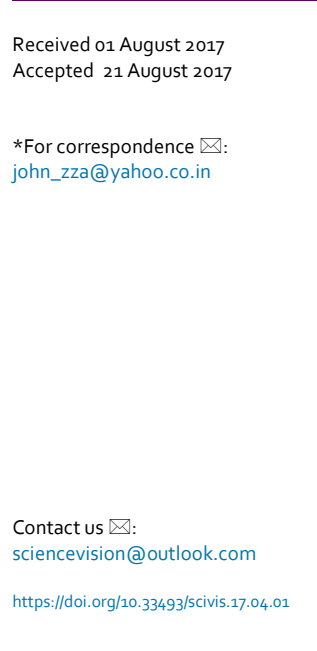

August 2017

*For correspondence $\square$ john_zza@yahoo.co.in

\section{Introduction}

The term mushrooms (macrofungi) or Macromycetes has been variously defined by several authors. They are the fleshy, spore-bearing fruiting bodies of fungi, which typically appear above ground after rain. ${ }^{1}$ They mostly grow in forests in association on woody parts of trees either as parasite, saprophyte or as symbionts in the soil. These mushrooms producing prominent sporocarps are categorized as gilled fungi, bracket fungi, coral fungi, jelly fungi, birds nest fungi and puffballs.? Wild edible mushrooms are a natural resource with a high nutritional value. ${ }^{3}$ Numerous varieties of edible mushrooms exist in nature with more than 1,100 species recorded so far, ${ }^{4}$ however, less than $25 \%$ are widely ac- cepted as food and only a few have attained the level of an item of commerce. ${ }^{5}$ Wild edible macrofungi are good source of proteins and contributing substantially to the diets of rural and poor people. ${ }^{6,7}$ They are also increasing source of income for small-scale enterprises in developing as well as developed countries., 8

Knowledge about wild edible mushrooms and their nutritional value has been documented from Assam, Arunachal Pradesh, Nagaland, Manipur and Meghalaya in Northeast India. ${ }^{10-17} \mathrm{~A}$ diverse group of flora and fauna have been documented from Mizoram. However, information regarding the mushrooms especially the edible mushroom from the state is very limited. Recently, investigations have been done on mushrooms and only few wild edible mush- 
rooms have so far been reported. ${ }^{18-23}$ The present study is a first attempt to study and record the occurrence of these wild edible mushrooms in the region with their taxonomical details as per standard mycological procedures.

\section{Materials and Methods}

\section{Study sites}

Mizoram lies in Northeast India sharing its borders with Assam, Manipur and Tripura and has international borders with Bangladesh and Myanmar. The geographical area is $21,081 \mathrm{sq} \mathrm{km}$ and lies between $21^{\circ} 58^{\prime}$ and $24^{\circ} 35^{\prime} \mathrm{N}$ Latitudes and $91^{\circ} 15^{\prime}$ and $92^{\circ} 29^{\circ} \mathrm{E}$ longitudes. The Tropic of
Cancer passes through the State at $23^{\circ} 30^{\prime} \mathrm{N}$ latitude. The edible mushrooms were collected from different places of Mizoram during the study. The collections were carried out in various districts of Mizoram from July 2013 to October 2016. The main collection sites are Hmuifang, Aizawl, Dampa, Murlen,Tawi, Reiek, Ailawng, Tuipang, Pualreng, Ngopa, Champhai, Sangau, E. Lungdar, Khawbung, Lawngtlai, Tanhril, Khawzawl, Phullen, Hnahthial, Lungsen, Zawlnuam, Bungtlang South and Thingdawl.

\section{Identification of specimens}

Collected specimens were identified according to standard macroscopic and microscopic

Table 1 | List of mushroom with local name, habitat and place of collection.

\begin{tabular}{|c|c|c|c|c|c|}
\hline $\begin{array}{l}\text { Sl. } \\
\text { No. }\end{array}$ & Scientific Name & Local Name & Family (Order) & Habitat & $\begin{array}{l}\text { Place of } \\
\text { collection }\end{array}$ \\
\hline 1. & Lactifluus corrugis & Pa uithin & Russulaceae (Russulales) & Soil & $11,12,13$ \\
\hline 2. & Auricularia auricula-judae & Pu Vana beng & Auriculariaceae (Auriculariales) & Wood & $1,2,3,5,6$ \\
\hline 3. & Cantharellus cibarius & -- & Cantharellaceae (Cantharellales) & Soil & $14,15,16$ \\
\hline 4. & Craterellus cornucopioides & -- & Cantharellaceae (Cantharellales) & Soil & 1,16 \\
\hline 5. & Fistulina hepatica & -- & Fistulinaceae (Agaricales) & Wood & 1,16 \\
\hline 6. & Lactarius piperatus & Pa lengvar & Russulaceae (Russulales) & Soil & $1,11,13,16,17$ \\
\hline 7. & Laetiporus sulphureus & -- & Polyporaceae (Polyporales) & Wood & 1 \\
\hline 8. & Lentinula edodes & -- & Marasmiaceae (Agaricales) & Wood & $1,3,4,6$ \\
\hline 9. & Lentinula lateritia & Pa pal & Marasmiaceae (Agaricales) & Wood & 4,11 \\
\hline 10. & Lentinus polychrous & Pa chang hang & Polyporaceae (Polyporales) & Wood & $4,5,18,19$ \\
\hline 11. & Lentinus tigrinus & Pa hnahkhar & Polyporaceae (Polyporales) & Wood & 9 \\
\hline 12. & Lentinus sajor-caju & -- & Polyporaceae (Polyporales) & Wood & 3 \\
\hline 13. & Lycoperdon perlatum & -- & Plutaceae (Agaricales) & Soil & 1 \\
\hline 14. & Macrolepiota dolichaula & Pa se-ek & Agaricaceae (Agaricales) & Soil & 1,11 \\
\hline 15. & Macrolepiota procera & -- & Agaricaceae(Agaricales) & Soil & 1,16 \\
\hline 16. & Pleurotus djamor & -- & Pleurotaceae (Agaricales) & Wood & $1,3,4,6$ \\
\hline 17. & Pleurotus ostreatus & -- & Pleurotaceae (Agaricales) & Wood & 1 \\
\hline 18. & Ramariopsis kunzei & -- & Clavariaceae (Phallales) & Soil & 15,16 \\
\hline 19. & Russula aurora & -- & Russulaceae (Russulales) & Soil & 1,11 \\
\hline 20. & Russula compacta & -- & Russulaceae (Russulales) & Soil & 14,16 \\
\hline 21. & Russula cyanoxantha & -- & Russulaceae (Russulales) & Soil & 1,11 \\
\hline 22. & Russula subfragiliformis & Pa lengsen & Russulaceae (Russulales) & Soil & 1,16 \\
\hline 23. & Schizophyllum commune & Pasi & Schizophyllaceae (Agaricales) & Wood & 1-23 (all sites) \\
\hline 24. & Termitomyces heimii & Pasawntlung & Lyophyllaceae (Agaricales) & Soil & $2-12,15,16,21$ \\
\hline 25. & Tremella fuciformis & -- & Tremellaceae (Tremellales) & Wood & $1,3,6$ \\
\hline 26. & Tremella mesenterica & -- & Tremellaceae (Tremellales) & Wood & 3,6 \\
\hline 27. & Volvariella taylorii & Changel pa & Plutaceae (Agaricales) & Soil & $1,15,16$ \\
\hline
\end{tabular}

*Place of collection: 1. Hmuifang; 2. Aizawl; 3. Dampa; 4. Murlen; 5. Tawi; 6. Reiek; 7. Ailawng; 8. Tuipang; 9. Pualreng 10. Ngopa; 11. Champhai; 12. Sangau; 13. E. Lungdar; 14. Khawbung; 15. Lawngtlai; 16. Tanhril; 17. Khawzawl; 18. Phullen; 19. Hnahthial; 20. Lungsen; 21. Zawlnuam; 22. Bungtlang South; 23. Thingdawl. 
characteristics through consultation with appropriate literatures. ${ }^{2426}$ The macroscopic characteristics such as shape, size and color of the basidiocarps were described from fresh specimens. Microscopic characteristics data were obtained from the fresh and dried specimen with the aid of a light microscope after sectioning and stained with $1 \%$ cotton-blue or safranin. Spore prints of the collected specimens were taken for microscopic observation. Spore prints were also taken on a micro slide and amyloidal reaction were checked in Melzer's reagent. Specimens were dried and deposited in the Mizoram University herbarium with voucher numbers.

\section{Results}

\section{Species list}

Table 1 and photoplates 1-27 shows the list of mushroom species identified and described alongwith the taxonomical position and the place of collection. The identified specimens were from the families - Russulaceae (6 species), Polyporaceae (4 species), Cantharellaceae (2 species), Plutaceae (2 species), Agaricaceae (2 species), Pleurotaceae (2 species), Tremellaceae (2 species), Marasmiaceae (2 species), Clavariaceae (1 species), Schizophyllaceae (1 species), Lyophyllaceae (1 species), Auriculariaceae (1 species) and Fistulinaceae (1 species).

\section{Species description}

The following is a general description with detailed features of the mushroom species from observation of macro and microscopic characteristics:

\section{Lactifluus corrugis (formerly Lactarius corrugis) (Peck) Kuntze (Photo plate 1) Local name (Mizo) - Pa uithin}

Cap 4-20 cm broad, convex at first becoming plane or shallowly depressed, minutely velvety to nearly smooth, dry, usually dark brownish red to dark brick red but sometimes purplish brown or dark brown. Flesh whitish to yellowish; stain- ing slowly brown when sliced, thick, firm but brittle. Latex white, copious, slowly staining brown or staining tissues brown. Gills adnate to slightly decurrent, close, pale buff when young but soon orange to yellowish or brownish, discoloring brown where injured. Stalk $3-11 \mathrm{~cm}$ long, $1.5-3 \mathrm{~cm}$ thick, colored more or less like the cap, brown to reddish brown or paler equal, solid. Sporeprint white. Spores 9-12 x 8.5-12 $\mu$, globose or subglobose, amyloid. Specimen examined: MZUEVS/SF/0014

Auricularia auricula-judae (Bull.) J. Schrot (Photo plate 2)

Local name (Mizo) - Pu Vana beng

Fruiting body wavy and irregular, typically ear-shaped, 2-15 cm, gathered together and attached at a central or lateral position, fertile surface (usually the "downward" one) gelatinous, tan to brown, sterile surface (usually the "upper" one) silky to downy, veined, irregular, brown. Flesh thin, gelatinous-rubbery. Sporeprint white. Spores 12-19 x 4-8 $\mu$, ellipsoid, sausage shaped, smooth. Specimen examined: MZUEVS/WF/0002.

\section{Cantharellus cibarius Fr. (Photo plate 3)}

Cap is $2-20 \mathrm{~cm}$ broad, broadly convex when young, becoming plane to depressed or vase shaped in age, surface smooth or occasionally cracked, not viscid, wavy irregular margin or lobed, at first margin incurved, light yellow or orange to deep egg-yolk yellow. Flesh is whitish to tinged yellow to orange under the cuticle, thick, firm. Gills well-spaced to close, shallow blunt, fold like, deeply decurrent gills which are often forked or cross-veined, colored like cap or more often paler. Stalk is $2-10 \mathrm{~cm}$ long, $0.5-5 \mathrm{~cm}$ thick, equal or tapered downward or sometimes enlarged at base, solid and dry. Odor mild. Spore print is creamy or yellow. Spores 6-10 x 4-6 $\mu$, smooth, ellipsoid. Specimen examined: MZUEVS/SF/0020.

Craterellus cornucopioides (L.) Pers. (Photo plate 4)

Cap is $2-8 \mathrm{~cm}$ broad, hollow at the center with the margin decurved at first, then spreading out and becoming wavy and split. The funnel- 
shaped cap has an in rolled margin. Surface not viscid, usually minutely scaly or scurvy, greybrown to dark grey or black. Flesh is thin, britlle but tough, colored like cap or paler. The outer (fertile or hymenial) surface is smooth to uneven, deeply decurrent wrinkles but not gills, grey, colored like cap but usually paler or grayer, in dry weather or in age whitish to buff coating of spore dust. Stalk is $01-5 \mathrm{~cm}$ long, $0.5-1 \mathrm{~cm}$ thick. The grey pruinose, longitudinally finely wrinkled stem is hollow right down to the base, towards which it tapers slightly. Spore print is whitish to buff or pale yellow. Spores 7-11 x 5-7 $\mu$, broadly ellipsoidal, smooth. Specimen examined: MZUEVS/SF/0030.

Fistulina hepatica (Schaeff.) With. (Photo plate 5) Cap upto $30 \mathrm{~cm}$ across, irregular in shape but often fan-shaped or tongue-like, sometimes fused laterally with other caps, velvety, or fairly smooth, the margin lobed, red, reddish orange, or liver colored. Pore Surface whitish or pale

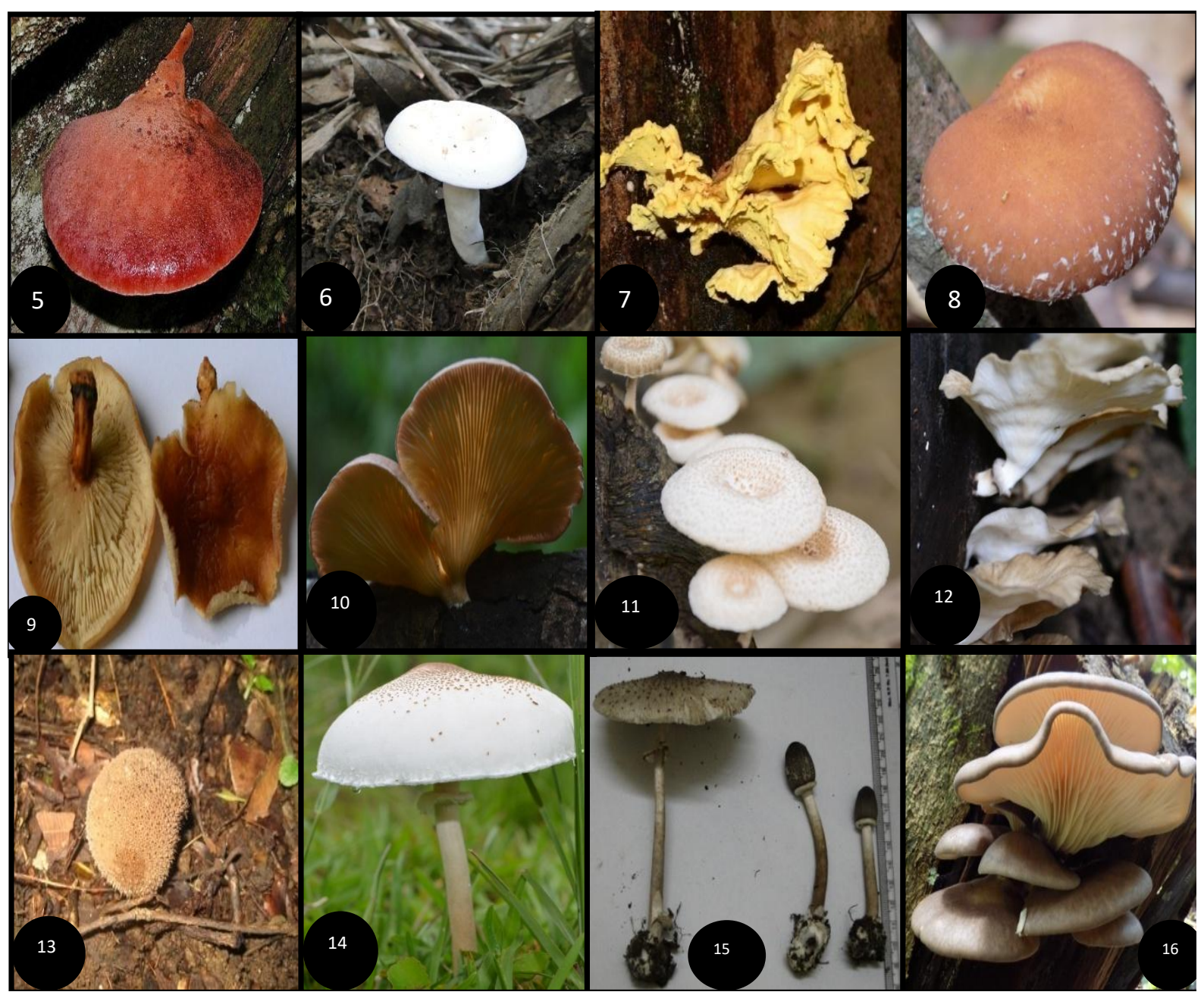

Photoplate (1-14) | 1. Lactifluus corrugis; 2. Auricularia auricula-judae; 3. Cantharellus cibarius; 4. Craterellus cornucopioides; 5. Fistulina hepatica; 6. Lactarius piperatus; 7. Laetiporus sulphureus; 8. Lentinula edodes; 9. Lentinula lateritia; 10. Lentinus polychrous; 11. Lentinus tigrinus; 12. Lentinus sajor-caju; 13. Lycoperdon perlatum; 14. Macrolepiota dolichaula; 15. Macrolepiota procera; 16 . Pleurotus ostreatus. 
pinkish, becoming reddish brown in age, bruising reddish brown. Flesh streaked with reddish areas, thick, soft, watery, exuding a reddish juice when squeezed. Odor not distinctive, taste sour or acidic. Spore print pinkish to pinkish brown. Spores 3.5-4.5 x 2.5-3 $\mu$, smooth, ovoid, inamyloid. Specimen examined: MZUEVS/WF/0004.

Lactarius piperatus(L.) Pers. (Photoplate 6) Local name (Mizo) - Pa lengvar

Cap 3-14cm broad, broadly convex, becoming flat, shallowly depressed, or vase-shaped, dry, the margin even, bald, white or whitish, sometimes discoloring a little yellowish or brownish with age. Flesh - white, thick, hard, sometimes discoloring yellowish with age. Milk copious, white, unchanging after exposure, or changing slowly to yellowish, not staining tissues, or staining them slightly yellowish, not staining white paper. Gills attached to the stem or running slightly down it, very crowded, forking frequently, white becoming pale cream. Stalk 2-7 $\mathrm{cm}$ long, $1-2.5 \mathrm{~cm}$ thick, white, more or less equal, or tapering a little to base, bald, without potholes, solid. Spore print white to off white. Spores 4-7 x 4.5-5.5 $\mu$, elliptical to nearly round with inconspicuous amyloid warts and ridges. Specimen examined: MZUEVS/SF/0036.

\section{Laetiporus sulphureus (Bull.) Murrill (Photo plate 7)}

Fruiting body up to $60 \mathrm{~cm}$ across usually consisting of several to many individual caps arranged in a shelving formation or a rosette. Cap $5-30 \mathrm{~cm}$ across and up to $20 \mathrm{~cm}$ deep, up to $3 \mathrm{~cm}$ thick, fan-shaped to semicircular or irregular, more or less plano-convex, smooth to finely wrinkled, bright yellow to bright orange when young, frequently fading in maturity and with direct sunlight. Pore surface yellow. Flesh thick, soft and watery when young, becoming tough, eventually crumbling away and white to pale yellow. Spore print white. Spores 5.5-7 x 3.5-5 $\mu$, smooth, elliptical to ovoid, inamyloid. Specimen examined: MZUEVS/WF/0005.

Lentinula edodes (Berg). Pegler (Photo plate 8)

Cap5-25 cm broad, black when young, dark brown to light brown with age and hemispheric, expanding to convex and planar at maturity. Gills white and even at first, serrated with age. Stalkfibrous and tough. Veil absent, mycelium white at first, becoming longitudinally linear and cottony-aerial in age, rarely rhizomorphic. In age or in response to damage, the mycelium becomes dark brown. Spore print white. Spores 5 $-6.5 \times 3-3.5 \mu$, ovoid to oblong ellipsoid. Specimen examined:MZUEVS/WF/0006.

\section{Lentinula lateritia (Berg). Pegler (Photo plate 9)}

Local name (Mizo) - Pa Pal

Fruiting body tan to reddish brown, margin slightly in rolled or wavy. Flesh white to cream. Gills free and white. Stalk tan to reddish brown covered with scales when mature. Spore print white to cream. Spores 3.3-4 × 5.8-6.5 $\mu$, subglobose to ellipsoid. Specimen examined: MZUEVS/ WF/0007.

Lentinus polychrous Lev. (Photo plate 10)

Local name (Mizo) - Pachang-hang

Fruiting body white to creamy, cap funnel shaped 3-7 $\mathrm{cm}$ broad. Gills creamy to white and decurrent towards stalk. Stalk 2-4 cm. Spore print white, Spores $2.5-3 \times 4.6-6.1 \mu$, ellipsoid and somewhat kidney shaped, inamyloid. Specimen examined: MZUEVS/WF/0008.

\section{Lentinus tigrinus (Bull.) Fr. (Photo plate 11)}

Local name (Mizo) - Pa hnahkhar

Fruiting body hat foreground convex and then depressed to infundibuliform and with recurved margin. Cuticle covered with scales, more brown to brownish blackish and tighter in the center. Gills decurrent, creamy white. Stalk cylindrical and slightly attenuated at base, central, whitish and covered with scales. Flesh fruity and slightly bitter taste. Spore 6.6$8.3 \times 3.4-4.1 \mu$, ellipsoidal, smooth. Specimen examined: MZUEVS/WF/0009.

Lentinus sajor-caju (Fr.) Fries. (Photo plate 12)

The fruiting body is extremely tough with a well-developed stout central stalk, there are lamellate gills on lower surface. There may be a fleshy collar at the base, it gets lost with age. 
Margins of cap rolled under when old and dry. 10-15 cm funnel shaped cap, annulus on the stipe. Spore print white. Spores 5-7 $\mu$ x 2-3 $\mu$ ellipisoid to cylindrical. Specimen examined: MZUEVS/WF/0010.

\section{Lycoperdon perlatum Pers. (Photo plate 13)}

Fruiting body shaped like an inverted pear or top-shaped with a rounded to flattened top, 1.5$6 \mathrm{~cm}$ broad $2-9 \mathrm{~cm}$ high. Outer layer of peridium or skin consists slender, short pyramidal warts, especially dense at the head, rubbing off to leave an indistinct mesh-like pattern beneath, which opens $u$ by a pore. Spines white to gray or in one form brown. Spore mass at first white to tan becoming yellowish-brown to grayish-brown or dark brown in old age, eventually rupturing through a pore at the top. Sterile base large, at first white and spongy, then yellow, olive, brown, or chocolate colored, occupying the stem. Spores 3.5-4.5 x 3.5-4.5 $\mu$, globose, minutely warted. Specimen examined: MZUEVS/ SF/0008.

Note: Edible when firm and white inside, but specimens showing the slightest traces of yellow should not be eaten.

Macrolepiota dolichaula (Berk. \& Broome) Pegler \& R.W. Rayner (Photo plate 14)

Local name (Mizo) - Pa se-ek

Cap 5-20 cm broad, at first oval, then expanding to convex or plane with umbonate at the center, surface dry, cap surface smooth at first but soon breaking up into light brown to brown or pinkish brown scales and patches on a white background, more concentrated darker scales at the central umbo margin bearing remnants of veil. Flesh white, thick, soft in age. Gills free, white when young but sometimes discoloring to pinkish white or dingy brownish in old age, broad, close. Stalk white and very tall, 5-16 cm long, $0.5-2 \mathrm{~cm}$ thick, bulbous at the base. Annulus persistent and membranous, ring collar like and movable, thick. Spore print white. Spores 8$15 \times 5-8 \mu$, broadly ellipsoidal, thick walled with an apical pore, dextrinoid. Specimen examined: MZUEVS/SF/0029.
Macrolepiota procera Scop. Fr. (Photo plate 15)

Cap 7-25 cm broad, oval when young, becoming convex to broadly convex in age, with a dark central bump, dry, at first smooth and brownish, soon becoming scaly, the scales brown, the surface below whitish and later grayish or brownish, often shaggy and torn-up at maturity. Flesh white throughout, sometimes tinged reddish, but not staining reddish when exposed; soft. Gills free from the stem, white when young, sometimes discoloring to pinkish or tan in maturity. Stalk $14-20 \mathrm{~cm}$ long, $0.5-1.5 \mathrm{~cm}$ thick, long and slender, with an enlarged base (but not swollen over the lower half, pale above the ring, below the ring with small brown scales that break up as the mushroom matures, creating zones or sometimes disappearing; with a double -edged ring that moves freely up and down the stem. Spore print white. Spores 10-15 x 8-8 $\mu$, broadly ellipsoidal, thick walled with an apical pore, dextrinoid. Specimen examined: MZUEVS/ SF/0035.

Pleurotus ostreatus (Jacq.) P. Kumm (Photo plate 16)

Cap 4-15 cm broad, convex, becoming flat or somewhat depressed, kidney-shaped to fanshaped, or nearly circular if growing on the tops of logs, somewhat greasy when young and fresh, smooth, pale brown to dark brown. Gills whitish or with a gray tinge, sometimes yellowish in age. Stalk usually rudimentary and lateral or absent when the mushroom is growing from the side of a $\log$ or tree. Spore print whitish to grayish. Spores 8-10.5 x 3-3.5 $\mu$, smooth, cylindrical to narrowly kidney-shaped. Specimen examined: MZUEVS/WF/0011.

Pleurotus djamor (Rumph. ex Fr.) Boedijn (Photo plate 17)

Cap 2-7 cm broad, convex, expanding with age to broadly convex to plane, laterally attached to the substrate, spatulate to bell-shaped, margin inrolled at first, then incurved, and eventually flattening and upturning at maturity, white to bright reddish pink, developing a dull to light pinkish cinnamon in age. Gills deeply decurrent and somewhat crowded, strongly pig- 
mented pinkish when young and fade to creamy white-beige at maturity. When over mature all parts of the mushroom lose pigmentation and fade to beige-white to straw colored extremely short. Spore print white to beige to pink. Pleurotus djamor exhibits a wide range of color morphology for spores as well as fruit bodies, the color of the fruit body directly influences the color of the spores. Spores 0.9-6.0-10.5 x 3-3.5 $\mu$, smooth, cylindrical. Specimen examined: MZUEVS/WF/0012.

Ramariopsis kunzei (Fr.) Donk (Photo plate 18)

Fruiting body $2.5-10 \mathrm{~cm}$ high, numerously branched, compound, white to creamy-white, often tinged with pink in age, smooth, scurvy, tips acute or blunt. Flesh white, pliant to fragile. Stalk absent or present only as a short up to 1 $\mathrm{cm}$, fragile, sometimes hairy base. Spore print white. Spores 3-5.5 x 2.5-4.5 $\mu$, broadly ellipsoid or subglobose, with minute spine. Specimen examined: MZUEVS/SF/0050

Russula aurora Krombh. (Photo plate 19)

Cap 4-9 cm broad, convex, becoming centrally depressed or flattening, purplish pink or red, usually creamy pink at the center, moderately thick-fleshed, firm brittle, dry, shiny, sometimes powdered, cuticle half peeling to center, developing slight striations at the mar-

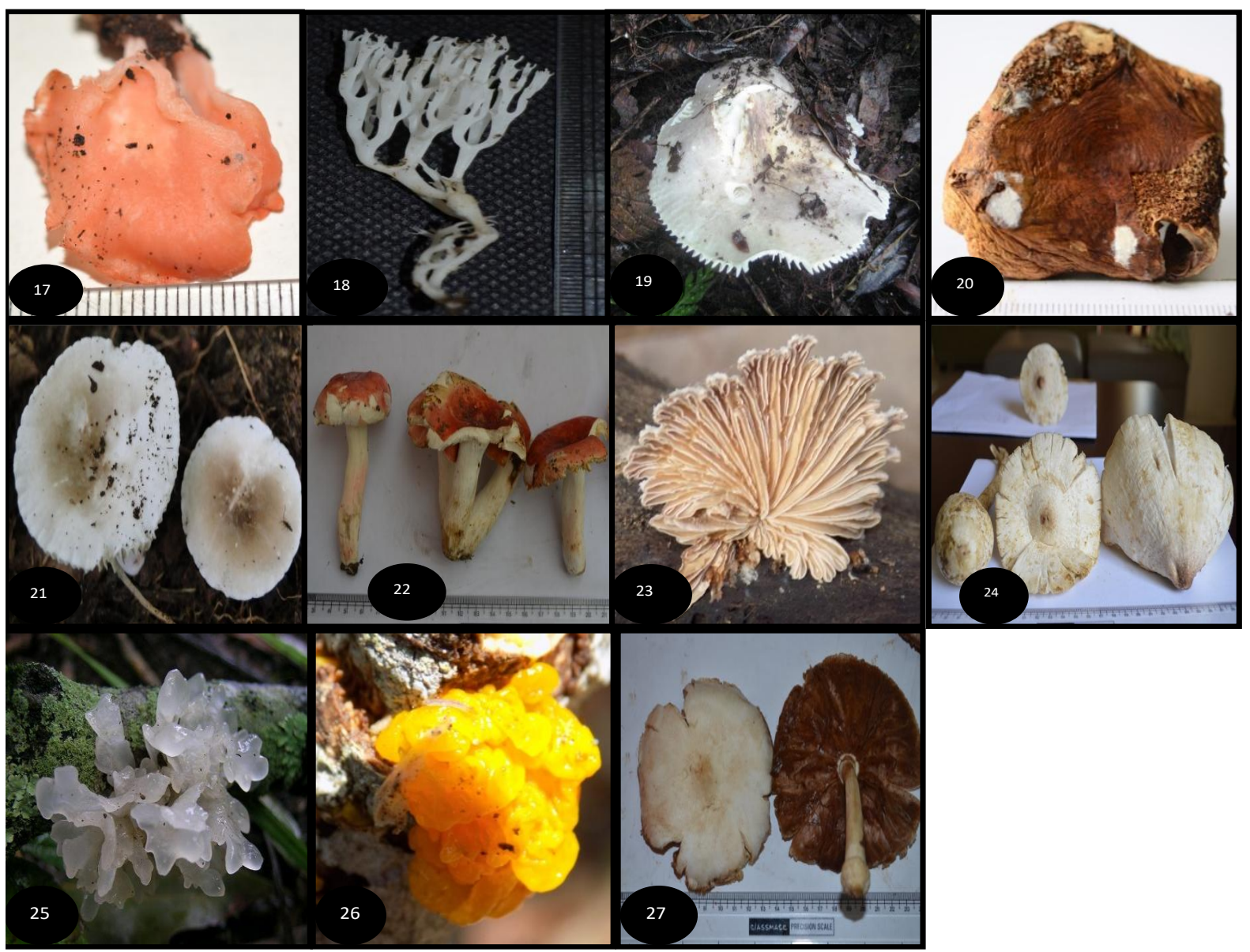

Photoplate (17-27) | 17. Pleurotus djamor; 18. Ramariopsis kunzei; 19. Russula aurora; 20. Russula compacta (dried); 21. Russula cyanoxantha; 22. Russula subfragiliformis; 23. Shizophyllum commune; 24. Termitomycetes heimii; 25. Tremella fuciformis; 26. Tremella mesenterica; 27 . Volvariella taylorii. 
gin. Flesh white, dry, brittle. Gills white to pale cream, nearly free, adnate or adnexed, fairly crowded, with some forked gills. Stalk $3-7 \mathrm{~cm}$ long, 1-2 cm thick, white, brittle, fairly fragile or somewhat firm. Spore print white to pale cream. Spores 6-8 x 5-6.5cm, ovate, warted. Specimen examined: MZUEVS/SF/0018.

\section{Russula compacta Frost (Photo plate 20)}

Cap 3-18 cm broad, cushion-shaped with incurved margin, convex to nearly flat, often with a slightly sunken center or vase-shaped, more or less smooth, dry but sticky and shiny when wet, often cracking, white to whitish or yelloworange when young, but soon discoloring dirty yellowish to reddish brown, and in age appearing completely tawny brown, bruising reddish brown, margin unlined. Flesh white, thick, firm, brittle, discoloring yellowish to yellowish brown or reddish brown on exposure. Gills adnate, crowded, close, or almost distant, white to pale cream-yellow, bruising and discoloring reddish brown. Stalk $2.5-10 \mathrm{~cm}$ long, $1-3 \mathrm{~cm}$ thick, sometimes enlarging or tapering toward base, dry, dull, mostly smooth to wrinkled, white but soon flushed reddish brown, solid, becoming hollow. Spore print white. Spores 7-9 × 6-8 $\mu$, broadly elliptical to oval, ornamented with low warts, amyloid. Specimen examined: MZUEVS/SF/0166.

Russula cyanoxantha (Schaeff.) Fr. (Photo plate 21)

Cap 5-15 cm broad, convex when young becoming broadly convex to flat with a shallow depression, fragile, dry or slightly greasy, smooth or radially wrinkled, streaked or cracked, extremely variable in color, usually shades of lilac to pinkish purple to green or olive green, the cuticle peeling about halfway to the center. Flesh white, brittle, thick. Gills white to pale cream, narrow, crowded, attached or slightly running down the stem, not forking, or forking occasionally, flexible and greasy to touch. Stalk 3-11 cm long, 1-3 cm thick, dry, smooth, white to yellowish white but occasionally flushed with lilac, solid, becoming hollow, brittle, dry, smooth. Spore print white. Spores 7$10 \times 5-8 \mu$, broadly ellipsoidal with isolated warts, amyloid. Specimen examined: MZUEVS/ SF/0004.

Russula subgragiliformis Murr. (Photo plate 22)

Local name (Mizo) - Pa lengsen

Cap 5-8 cm broad, convex to nearly flat, often with a slightly sunken center or vase-shaped, more or less smooth, red to pinkish red, dry but sticky and shiny when wet, incurved margin, unlined. Flesh white, thick, firm, brittle. Gills almost distant, white to pale cream-yellow, bruising and discoloring on exposure. Stem 2-6 $\mathrm{cm}$ long, 1-2 cm long, thick, equal, dry, brittle, firm, white but soon partly pink, solid, becoming hollow. Spore print white. Spores 6-8 x 5-7.5 $\mu$, elliptical to ovate, ornamented with warts, amyloid. Specimen examined: MZUEVS/SF/0039.

Schizophyllum commune Fries. (Photo plate 23) Local name (Mizo) - Pasi

Fruiting Body 1-5 cm wide, fan-shaped when attached to the side of the log, irregular to shellshaped when attached above or below, upper surface covered with small hairs, dry, white to grayish or tan, under surface composed of gilllike folds that are split down the middle, whitish to grayish, without a stem. Flesh tough, leathery. Spore print white. Spores 3-5 x 1-2.5 $\mu$, cylindrical to elliptical, smooth. Specimen examined: MZUEVS/WF/0001.

Termitomyces heimii Natarajan (Photo plate 25) Local name (Mizo) - Pasawntlung

Cap 4-8 cm in diameter, white with the umbo region when young, grey and brownish grey when mature, context fleshy white, glabrous, surface smooth, convex to plano-convex with eroded margin, prominently sub-umbonate when young. Stalk white, smooth, cylindrical, equal and fleshy measuring $7-18 \mathrm{~cm}$ in length and $1-2 \mathrm{~cm}$ in width. Lamellae present, white to pink, crowded and free. Spore print pink, with a brownish tinge. Annulus present. Volva absent. Spores 5-7.5 x 3-5 $\mu$, hyaline, ellipsoid, thin walled measuring. Specimen examined: MZUEVS/SF/0016.

Tremella fuciformis (Berk.) (Photo plate 26) 
Fruiting body gelatinous but fairly firm, composed of graceful lobes, translucent whitish, up to about $7 \mathrm{~cm}$ across and $4 \mathrm{~cm}$ high, surface smooth and shiny. Spore print white. Spores 7$14 \times$ 5-8.5 $\mu$, ovoid, smooth. Specimen examined: MZUEVS/WF/0013.

Tremella mesenterica Retz. (Photo plate 27)

Fruiting Body gelatinous; when young and fresh composed of lobes or brain like sections, but rather formless in age or in wet weather, up to about $5 \mathrm{~cm}$ across; orange to yellow, fading when mature or when wet, without a stem; sometimes becoming tough and crust like when dried out. Spore print whitish or pale yellowish. Spores 10-15.5 $\times$ 7-12 $\mu$, elliptical to oval, smooth. Specimen examined: MZUEVS/WF/0003.

\section{Volvariella taylorii (Berk. \& Broome) (Photo plate} 28)

Cap 2-6 cm broad, convex or broadly conic, becoming broadly convex to nearly flat, dry, finely hairy, grayish to brownish gray, margin not lined. Flesh white. Gills free from the stem, whitish becoming pink, close or almost distant. Stalk 3-6.5 cm long, 3-7 mm thick, tapering gradually to apex, with a slightly swollen base, dry, whitish or grayish, smooth or at the apex, finely hairy, the base encased in a thick, gray to brownish, sack-like volva. Spore print salmon pink. Spores 5.5-9 x 4-6 $\mu$, more or less elliptical, or somewhat ovoid, smooth. Specimen examined: MZUEVS/SF/0007.

\section{Discussion and Conclusion}

A total of 27 species were identified and described according to standard procedures representing 18 genera constituting 13 families and 7 orders. The identified edible mushroom species includes 14 species growing in soil and 13 wood inhabiting.

The Mizo people of Mizoram have a very limited knowledge on edible mushrooms. Only few species of edible mushrooms are known and consumed/eaten by the Mizos at present. Woodinhabiting fungi or mushrooms namely Schizophyllum commune (pasi), Lentinula lateritia (pa pal),
Auricularia auricular-judae ( $\mathrm{Pu}$ Vana beng), Lentinus tigrinus (pa hnahkhar), Lentinus polychrous (pa chang/pa puanveng) and soil growing fungi viz., Lactifluus corrugis (pa uithin), Lactarius piperatus (pa lengvar), Russula subfragiliformis (pa lengsen), Macrolepiota dolichaula (pa se-ek) Termotomyces heimii (pasawntlung), Volvariella taylorii (changel pa) are the commonly known species. These mushrooms are widely found in the market places and have fair economic value for the rural people. The other species described in this paper are not yet known to the Mizo community as edible. For example, Tremella fuciformis and Tremella mesenterica plays a great role in Chinese and Japanese cuisine and are known to have great medicinal value. Similarly, Cantharellus cibarius, Craterellus cornucopioides, Lycoperdon perlatum, Lentinula edodes, Lentinus sajor-caju, Macrolepiota procera, Pleurotus djamor, P. ostreatus, Ramariopsis kunzei, Russula aurora, R. compacta, R. cyanoxantha and the other species such as Laetiporus suphureus (chicken of the woods) and Fistulina hepatica (beef steak fungus) are choice edible mushrooms in many parts of the world but are yet unknown to the local community in Mizoram. From the study, it is assumed that wider and intensive study in the various forests of Mizoram may yield more information on the presence of other species of edible mushrooms.

\section{Acknowledgements}

The authors thanked the NLUP Implementing Board, Government of Mizoram for financial support and assistance in the collection of the samples from various areas of Mizoram. We also thanked Mizoram University for financial support through the UGC PhD Fellowship grant and the DST-SERB Project grant (DST-SERB Sanction Letter No.SB/EMEQ-160/2014). Thanks also to Prof. Robert A. Blanchette, Department of Plant Pathology, University of Minnesota, USA, for extending help in confirming some of the species.

\section{References}

I. Ainsworth, G. C., Bisby, Richard, G. \& Kirk, P.M. (1950). A Dictionary of the Fungi (9 ${ }^{\text {th }}$ editions.), CABI 
Bioscience, U.K.

2. Bates, S. C., (2006). A preliminary Checklist of Arizona Macrofungi. Canotia. 2, 47-78.

3. Khaund, P. \& Joshi, S.R. (2013). Wild edible macrofungal species consumed by the Khasi tribe of Meghalaya, India. Indian Journal of Natural Products and Resources. 4, 197-204.

4. Boa, E. (2004b). Non Wood Forest Product. (17). FAO, Rome, pp. I-I47.

5. Smith, J. (1972). Commercial mushroom production. Process Biochemistry. 7: 24-26.

6. Adewusi, S.R.A., Alofe, F.V., Odeyami, O., Afolabi, O.A. \& Oke, O.L. (1993). Studies on some edible wild mushrooms from Nigeria: I teratogenic and toxic consideration. Plant Food Human Nutrition. 43: II5-I2I.

7. Aletor, V.A. (1995). Compositional studies on edible tropical specials of mushroom. Food Chemistry. 54: 256268.

8. Hosford, D., Pilz, D., Molina, P. \& Amaranthus, M. (1997). Ecology and management of commercially harvested American Matsutake mushroom, General Technical Report PNW-GTR-4I2, USDA Forest Service Pacific Northwest Research Station, pp. I-68.

9. Wong, J.L.G., Thornber, K. \& Baker, N. (200I). NonWood Forest Products 13. FAO, Rome, 68(3): 22I- 26.

Io. Sarma, T.C., Sarma, I. \& Patiri, B.N. (20I0). Wild edible mushrooms used by some ethnic tribes of western assam. The Bioscan 3 (Special issue): 613-625.

II. Tanti, B., Gurung, L. \& Sharma, G.C. (2OII). Wild edible fungal resources used by ethnic tribes of Nagaland, India. Indian Journal of Traditional Knowledge $\mathbf{1 0}, 5 \mathrm{I} 2-$ 515.

I2. Tapwal, A., Kumar, R. \& Pandey, S. (2013). Diversity and frequency of macrofungi associated with wet ever green tropical forest in Assam, India. International Journal of biological diversity, Biodiversitas $\mathbf{1 4}$ (2), 73-78.

13. Kumar, R., Tapwal, A., Pandey, S., Borah, K.R., Borah, D. \& Borgohain, J. (2013). Macro-fungal diversity and nutrient content of some edible mushrooms of $\mathrm{Na}$ galand, India. An International Journal of Nusentara, Bioscience, Indonesia 5(I), I-7.

14. Kumar, R., Pandey, S., Tapwal, A., Rishi, R., Giri, K. \& Mishra, G. (2014). Ethnomycological Knowledge on Wild Mushrooms by tribes of Mokokchung, Nagaland, North East India. The Journal of Ethnobiology and Traditional Medicine. Photon 122, 890-899.

I5. Kumar, R., Bisht, N.S., Mishra, G., Kalita, K. \& Bezbaroa, N.R. (2015). Micro and macrofungal diversity in
Langol herbal garden Manipur, India. An international Journal of Current Life Sciences I, 24-34.

16. Barua, P., Adhikary, R.K., Kalita, P., Bordoloi, D., Gogol, A., Singh, R.S. \& Ghosh, A.C. (1998). Wild edible mushrooms of Meghalaya. Ancient Science of Life I7, I-4.

17. Agrahar, M.D. \& Subbulakshmi, G. (2005). Nutritional value of edible wild mushrooms collected from the Khasi hills of Meghalaya. Food Chemistry 89, 599-603.

18. Bisht, N.S. (2011). Wood decaying fungi of Mizoram. Department of Environment and Forest, Government of India. pp. I-196.

19. Zothanzama, J. (20II). Wood Rotting Fungi of Mizoram. In H.vLalramnghinglova and F.vLalnunmawia (eds). Forest Resources of Mizoram: Conservation and Management. Department of Environmental Science, Mizoram University and Regional Centre, National Afforestation and Eco-development Board; North Eastern Hill University, pp. 326-345.

2o. Zothanzama, J. \& Lalrinawmi, H. (2015). Wild Edible Mushroom of Mizoram. In K. Eckman and L. Ralte; Integrated Land Use Management in the Eastern Himalayas. Akansha Publishing House, New Delhi, pp. I7I-I8I.

2I. Zothanzama, J., Blanchette, R., Redford, S., Zohmangaiha \& Vabeikhokhei, J.M.C., (2016). Using molecular characterization as a tool for identification of fungi of Mizoram In K. Eckman and L. Ralte; Integrated Land Use Management in the Eastern Himalayas. Akansha Publishing House, New Delhi, pp. 165-177.

22. Lalrinawmi, H. \& Zothanzama, J. (2016). A report on soil macrofungi in some selected sites of Mizoram. In Current Trends of Biodiversity Research in Mizoram. H. Lalramnghinglova, Vanramliana and H. Lalthanzara (Editions). (2016). Scientific Book Centre, Guwahati, pp. I32-I4I.

23. Lalrinawmi, H. \& Zothanzama, J. (2016). Wild Mushrooms of Hmuifang Forest, Mizoram. Science and Technology for shaping the future of Mizoram: Proceedings of the Mizoram Science Congress, 20I6. Allied Publishers Private Limited, New Delhi, pp. 33I-337.

24. Arora, D. (1986). Mushrooms Demystified (2 ${ }^{\text {nd }}$ editions). Ten Speed Press, New York, pp. 959.

25. Mohanan, C. (2013). Mushrooms of Kerala. Kerala State Biodiversity Board, pp. 57.

26. Phillips, R. (2010). Mushrooms and other Fungi of North America. Firefly Books, New York, pp. 384. 